\title{
Current research on profile monitoring
}

\begin{abstract}
In many applications the quality of a process or product is best characterized and summarized by a functional relationship between a response variable and one or more explanatory variables. Profile monitoring is used to understand and to check the stability of this relationship over time. At each sampling stage one observes a collection of data points that can be represented by a curve (or profile). In some calibration applications, the profile can be represented adequately by a simple linear regression model, while in other applications more complicated models are needed. The purposes of this paper are to review recent research on the use of control charts to monitor process and product quality profiles and to encourage further research in this area.
\end{abstract}

\section{Key words}

Calibration, functional data analysis, linear regression, multivariate quality control, nonlinear regression, statistical process control, wavelets.

\section{Atuais pesquisas em monitoramento de perfis}

\section{Resumo}

Em muitas aplicações a qualidade de um processo ou de um produto é melhor caracterizada e descrita por uma relação funcional entre a variável resposta e uma ou mais variáveis explicativas. Monitoramento de perfis é usado para entender e checar a estabilidade desta relação ao longo do tempo. Cada vez que uma amostra é selecionada, uma coleção de pontos que pode ser representada por uma curva (ou perfil) é observada. Em algumas aplicações de calibração, o perfil pode ser representado adequadamente por um modelo de regressão linear simples, enquanto que em outras aplicações, modelos mais complicados serão necessários. Os objetivos deste artigo são: apresentar e resumir pesquisas recentes do uso de cartas de controle para monitorar perfis de processo e qualidade de produto e encorajar futuras pesquisas nesta área.

\section{Palavras-chave}

Calibração, análise de dados funcionais, regressão linear, controle de qualidade multivariada, regressão não linear, controle estatístico de processo, ondaletas. 


\section{INTRODUCTION}

Profile monitoring is the use of control charts for cases in which the quality of a process or product can be characterized by a functional relationship between a response variable and one or more explanatory variables. These cases appear to be increasingly common in practical applications. For each profile we assume that $n(n>1)$ values of a response variable $(Y)$ are measured along with the corresponding values of one or more explanatory variables (the $X$ 's). Except in the paper by Mosesova et al. (2007), it is assumed that each subgroup consists of a single profile. The reader is referred to Woodall et al. (2004) or Woodall (2007) for more detailed and comprehensive reviews of profile monitoring methods. This is a relatively new area of research, but it is growing rapidly.

Briefly summarizing, Woodall et al. (2004) highlighted the following important issues when monitoring profiles:

1. the usefulness of carefully distinguishing between Phase I and Phase II applications,

2. the decision regarding whether or not to include some between profile variation in common cause variation,

3. the use of methods capable of detecting any type of shift in the shape of the profile, and

4. the use of the simplest adequate profile model.

An effort has been made here not to cite references that were given in Woodall et al. (2004). In fact, roughly two-thirds of the fifty or so papers cited in this paper were published in 2006, were published or scheduled to appear in 2007, or are still under review.

Either parametric models or nonparametric methods can be used in both phases. In many cases of profile monitoring it is efficient to summarize the in-control shape of the profile with a parametric model and monitor for shifts in the parameters of this model. The control charts are based on the estimated parameters of the model from successive profile data observed over time. For nonparametric methods one can alternatively monitor metrics that reflect the discrepancies between observed profiles and a baseline profile established using historical Phase I data.

In some cases it is not clear what would be included under the heading of "profile monitoring". Under the definition of profile monitoring used in this paper, applications where times series data are collected on a number of individuals are not necessarily included unless, for instance, at each sampling time point one observes a time series with a differing time index. For example, an important quality of an automobile airbag is the pressure inside the bag as a function of the time since deployment. In this application one would have time series data collected each time an airbag is tested over time. Thus, this would qualify as a profile monitoring application.
The methods of Jiang et al. (2007), however, would not qualify as profile monitoring under the definition considered. In their application the data consist of times series for each of a number of customers. Changes in the shape of the customers' time series over time was of interest. Some might refer to the specified shape of the out-of-control shift of univariate time series data as a "profile", but this does not qualify under the definition used here. In addition, cases for which data are collected on multiple time series, which are possibly cross-correlated, are not necessarily included unless a model is used at each time period to represent the response variable. Thus, for example, the method of Brown et al. (2004) would not be included as a profile monitoring method, although it is a useful approach. In their application multiple time series data taken along the cross-section of paper during manufacture were broken into successive data segments. A stochastic model was fit to each segment and the estimated parameters were used as input into multivariate control chart methods. In this case, however, there is only one time index and there is no functional data analysis component to the problem.

\section{USE OF SIMPLE LINEAR REGRESSION}

Most of the work on profile monitoring has been for the case in which the profile can be adequately represented by a simple linear regression model. Calibration processes are often characterized by such linear functions. Chang and Gan (2006) proposed some Shewhart control charts for monitoring the slopes of relationships between two or more measurement processes in order to assure their accuracy. Monitoring of slopes of regression lines was also considered by Zhu and Lin (2007) in Phase I and in Phase II. Noorossana et al. (2004a) proposed a new method for monitoring simple linear regression profiles based on the multivariate control chart method of Healy (1987).

Mahmoud et al. (2007) and Zou, Zhang, and Wang (2006) considered change-point methods for detecting changes in the parameters of a simple linear regression model. These authors considered Phase I and Phase II applications, respectively. A self-starting method was proposed by Zou, Wang, and Tsung (2007), which avoids, to the extent possible, the distinction between Phase I and Phase II.

ISO 5725-6(1994) recommended a method for monitoring a linear calibration line based on the measurement of three standards at each time period. These standards are at low, medium and high values, respectively. The three deviations of the measured values from these standards are plotted simultaneously for each sample on a Shewhart-type control chart. Gupta et al. (2006) showed, however, that the use of control charts based on the estimated regression parameters is more effective in terms of run length performance. This 
latter approach is also more interpretable, particularly as the number of standards measured at each time period increases. The NIST / SEMATECH e-Handbook of Statistical Methods, which is freely available online at http:/www.itl. nist.gov/div898/handbook/, contains a discussion of the online methods recommended by ISO 5725-6 (1994).

A standard assumption in the monitoring of simple linear regression profiles is that the errors are independent and identically distributed, usually with an assumed normal distribution. Noorossana et al. (2007a, b) studied the effect of ignoring autocorrelation of the errors. Autocorrelated errors frequently occur within profile monitoring data because successive measurements are often made close in space and/or time. Noorossana et al. (2004b) studied the effect of non-normality of the error terms, using $t$-distributions as alternatives, on the performance of the EWMA/R method of Kang and Albin (2000).

\section{OTHER PROFILE MODELING APPROACHES}

In many applications the simple linear regression model is not sufficient to represent the shape of a profile, so more complicated methods are needed. Some of these models are discussed in this section.

\section{Multiple and Polynomial Regression}

Kazemzadehetal.(2007a)andMahmoud(2007)proposed Phase I methods for profiles represented by polynomial and multiple regression models, respectively. These authors each extended some of the simple linear regression profile methods. In particular, Kazemzadeh et al. (2007a) compared the $F$-statistic method of Mahmoud and Woodall (2004), the change-point method of Mahmoud et al. (2007), and a method based on $\mathrm{T}^{2}$ statistics for detecting a step shift in the regression parameters. Mahmoud (2007), on the other hand, compared the $F$-statistic method of Mahmoud and Woodall (2004) with a $\mathrm{T}^{2}$-based method. Kazemzadeh et al. (2007b) considered the Phase II monitoring of polynomial regression profiles.

Zou, Wang, and Tsung (2007) also considered multiple regression models through a general linear model framework. The authors employed multivariate EWMA charts and considered diagnostic methods after an outof-control signal, including a change-point approach. An example from semiconductor manufacturing was used as an illustration. A calibration example requiring multiple regression methods was the motivation of the work of Parker and Finley (2007).

\section{Nonlinear Regression Models}

Ding et al. (2006) used several types of data reduction methods for nonlinear profile data, in particular principal component analysis and independent component analysis. These authors also studied methods for cluster analysis for profile data.

Williams, Birch, Woodall, and Ferry (2007) used the nonlinear regression approach of Williams, Woodall, and Birch (2007) to monitor dose-response profiles used in high- throughput screening, using illustrative data provided by DuPont. A four-parameter logistic regression model was used to represent the profiles. The focus in these papers was on monitoring the parameters of the nonlinear regression model. Only a couple of forms of nonlinear regression models have been studied thus far in this way.

Moguerza et al. (2007) used support vector machines to monitor the fitted curves themselves instead of monitoring the parameters of models fitting the curves. Their approach is contrasted with that of Williams, Woodall, and Birch (2007) using the same set of particleboard vertical density profile data.

Chen and Nembhard (2007) proposed a high-dimensional control chart approach to profile monitoring based on the adaptive Neyman test statistic for the coefficients of discrete Fourier transforms of profiles. They investigated the performance of their method for both linear and nonlinear profiles.

\section{Mixed Models}

In most linear models applied to profile data it is assumed that the errors are independent and identically distributed random variables. In some cases, however, the errors may be autocorrelated. This generalization was studied by Jensen et al. (2007) and Jensen and Birch (2007) for simple and nonlinear regression, respectively, using mixed models. Jensen and Birch (2007) showed that the use of mixed models could have significant advantages when nonlinear regression models are used.

Mosesova et al. (2007) also proposed a mixed model approach with an example from the automotive industry. Among other issues, these authors discussed the issue of curve registration, i.e., aligning the curves prior to analysis. This step is needed in some applications.

\section{Use of Wavelets}

Wavelets continue to be a popular way to represent profile data when simple models cannot adequately represent the shape of the profile. Reis and Saraiva (2006) used wavelets to represent the surface of paper. Zhou, Sun and Shi (2007), Jeong, Lu and Wang (2006), and Chicken and Pignatiello (2007) also proposed wavelet-based methods. Wavelet methods are usually recommended when the shape of the profiles is too complicated for linear and nonlinear models to work well. As pointed out by Woodall et al. (2004), however, one should keep in mind that monitoring only a subset of 
the most significant wavelet coefficients based on in-control data can be dangerous in the sense that some out-of-control function changes will not be detectable.

\section{OTHER APPLICATIONS}

The profile monitoring framework includes applications in which numerous measurements of the same variable, e.g., a dimension such as thickness, are made at several locations on each manufactured part. Staudhammer, Maness, and Kozak (2007 a, b) proposed control charting methods for lumber manufacturing. In their application a laser was used to make dimensional measurements along each board at several locations. It was important to detect process faults which could result in boards not being the desired shape. In this application the key out-of-control shapes in the boards could be specified in advance. Schajer et al. (2004) described the measurement system used to obtain the lumber profile data.

Colosimo et al. (2007 b, d) proposed methods for monitoring dimensional requirements on manufactured items, with a focus on the monitoring of roundness. Colosimo et al. (2007a) considered the monitoring of more general shapes and surfaces. Colosimo et al. (2007c) compared a principal component approach to a method more commonly used in industry for profile monitoring described by Boeing (1998). The monitoring of shapes is a very promising area of research since the shape of manufactured items is very often an important aspect of quality. These researchers have shown that the standard methods for monitoring shape data are not as efficient as profile monitoring approaches. In some cases the current methods do not use all of the information in the data. For example, a standard metric for measuring roundness is the difference between the radii of the smallest circle containing the circular profile data and the largest circle falling within the profile data.

There have been two papers where the profiles correspond to infrared spectra. Marengo et al. (2005) considered an example involving organic pigments applied to cotton surfaces. Sahni et al. (2005), on the other hand, considered an example related to the shelf-life of a food product.

Wang and Tsung (2005) used profile monitoring methods to detect changes in a Q-Q plot which reflected the relationship between the current sample and a baseline sample. A closely related approach was proposed by Grimshaw and Alt (1997).
Jin (2004) proposed a very useful and relatively simple method in which the range of the independent $X$-variable is divided into $p$ segments. A shift within a segment would be associated with a particular type of process fault. The recommendation was to use $p$-dimensional Hotelling's $\mathrm{T}^{2}$ methods. This interesting approach is closely related to the approach proposed earlier by Young et al. (1999) who were monitoring the density profiles of particleboard. It is very reasonable to break the profile range up into subregions if process faults tend to affect a specific portion of the profile, as opposed to changing the profile over its entire range.

Several authors have discussed monitoring for "cyclebased signals." These signals are obtained using automated sensing during each repetitive operation of a manufacturing process. A common example is the tonnage signal (forming force) as measured by the strain gauge sensors installed on a forging press machine. Zhou et al. (2005) presented a method for the monitoring of such profiles when certain specified deviations in the shape of the profiles were known for some process faults. Their method was based on the approach of Healy (1987).

Finally, it was pointed out by Woodall (2006) that profile monitoring ideas could be applied in public health surveillance where the interest is in detecting clusters of increased disease rates over time. Thus, the approach of Zhou and Lawson (2007) would fall into the category of profile monitoring. In this application one can consider the incidence rate pattern to be a surface over the region of interest where the focus is to detect any increase over the in-control rate over any subregion.

\section{CONCLUSIONS}

Profile monitoring is very useful in an increasing number of practical applications. Much of the work in the past few years has focused on the use of more effective charting methods, the study of more general shapes of profiles, and the study of the effects of violations of assumptions. There are many promising research topics yet to be pursued given the broad range of profile shapes and possible models. There has been, to my knowledge, no discussion on assessing process capability with profile data. Some information and references have been given in this paper that should be helpful to those interested in research in profile monitoring or in its practical application. 


\section{- References}

Boeing Commercial Airplane Group, Materiel Division, Procurement Quality Assurance Department. Advanced Quality System Tools, AQS D1-9000-1, The Boeing Company: Seattle, WA, 1998.

BROWN, P. E.; DIGGLE, P. J.; HENDERSON, R. A Model-Based Approach to Quality Control of Paper Production. Applied Stochastic Models in Business and Industry, v. 20, p. 173-184, 2004.

CHANG, T. C.; GAN, F. F. Monitoring Linearity of Measurement Gauges. Journal of Statistical Computation and Simulation, v. 76, p. 889-911, 2006.

CHEN, S.; NEMBHARD, H. B. A HighDimensional Control Chart for Profile Monitoring, resubmitted to Technometrics, 2007.

CHICKEN, E.; PIGNATIELLO, J. J. JR.; SIMPSON, J. Statistical Process Monitoring of Nonlinear Profiles Using Wavelets, paper presented at the 51st Fall Technical Conference, Jacksonville FL, 2007.

COLOSIMO, B. M.; MAMMARELLA, F.; PETRÒ, S. Quality Control of Manufactured Surfaces, IX International Workshop on Intelligent Statistical Quality Control, Tsinghua University, Beijing, Sept. 1214, 2007a.

COLOSIMO, B. M.; PACELLA, M. On the Use of Principal Component Analysis to Identify Systematic Patterns in Roundness Profiles. Quality and Reliability Engineering International, to appear. 2007b.

COLOSIMO, B. M.; PACELLA, M. Control Charts for Functional Data: A Comparison Study. VIII Convegno A.I.Te.M. (Italian Association on Manufacturing), 2007. Montecatini Terme, September 10-12, 2007c.

COLOSIMO, B. M., PACELLA, M.; SEMERARO, Q. Statistical Process Control for Geometric Specifications: On the Monitoring of Roundness Profiles, Journal of Quality Technology, to appear, 2007d.

DING, Y., ZENG, L.; ZHOU, S. Phase I Analysis for Monitoring Nonlinear Profiles in Manufacturing Processes. Journal of Quality Technology, v. 38, p. $199-216,2006$

GRIMSHAW, S. D.; ALT, F. B. Control Charts for Quantile Function Values. Journal of Quality Technology, v. 29. p. 1-7, 1997.
GUPTA, S.; MONTGOMERY, D. C. Profiles - Monitoring the Variance Components, paper presented at the Joint Statistical Meetings, Salt Lake City, Utah, 2007.

GUPTA, S.; MONTGOMERY, D. C. WOODALL, W. H. Performance Evaluation of Two Methods for Online Monitoring of Linear Calibration Profiles, International Journal of Production Research, v. 44, p. 1927-1942, 2006.

HEALY, J. D. A Note on Multivariate CUSUM Procedures, Technometrics v. 29, p. 409-412, 1987.

ISO 5725-6. Accuracy (Trueness and Precision) of Measurement Methods and Results - Part 6. Internationa Organization for Standardization: Geneva, Switzerland, 1994.

JENSEN, W. A.; BIRCH, J. B. Monitoring Correlation within Nonlinear Profiles Using Mixed Models, under second review by Journal of Quality Technology, 2007

JENSEN, W. A., BIRCH, J. B., AND WOODALL, W. H. Monitoring Correlation within Linear Profiles Using Mixed Models, to appear in Journal of Quality Technology, 2007.

JENSEN, W. A.; JONES-FARMER, L. A.; CHAMP, C. W.; WOODALL, W. H. Effect of Parameter Estimation on Control Chart Properties: A Literature Review, Journal of Quality Technology, v. 38, p. 349-364, 2006

JEONG, M. K.; LU, J. C.; WANG, N. Waveletbased SPC Procedure for Complicated Functional Data, International Journal of Production Research, v. 44, p. 729-744, 2006

JIANG, W.; AU, T.; TSUI, K. L. A Statistica Process Control Approach to Business Activity Monitoring, IIE Transactions, v. 29, p. 235-249, 2007.

JIN, J. Individual Station Monitoring Using Press Tonnage Sensors for Multiple Operation Stamping Processes. Journal of Manufacturing Science and Engineering, v. 126, p. 83-90, 2004.

KANG, L.; ALBIN, S. L. On-Line Monitoring when the Process Yields a Linear Profile, Journal of Quality Technology, v. 32, p. 418-426, 2000
KAZEMZADEH, R B : NOOROSSANA, R.; AMIRI, A. Phase I Monitoring of Polynomial Profiles, to appear in Communications in Statistics - Theory and Methods, 2007a.

KAZEMZADEH, R.B.; NOOROSSANA, R.; AMIRI, A. On the Monitoring of Polynomial Profiles, Submitted to International Journal of Advanced Manufacturing Technology. Tentative acceptance subject to minor corrections, 2007b.

MAHMOUD, M. A. Phase I Analysis of Multiple Regression Linear Profiles, submitted for publication, 2007.

MAHMOUD, M. A.; PARKER, P. A.; WOODALL, W. H.; HAWKINS, D. M. A Change Point Method for Linear Profile Data, Quality \& Reliability Engineering International, v. 23, p. 247-268, 2007.

MAHMOUD, M. A.; WOODALL, W. H. Phase I Analysis of Linear Profiles with Calibration Applications, Technometrics, v. 46, p. 377-391, 2004.

MARENGO E.; LIPAROTA, M. C.; ROBOTTI, E.; BOBBA, M.; GENNARO, M. C. Monitoring of Pigmented Surfaces in Accelerated Ageing Process by ATRFT-IR Spectroscopy and Multivariate Control Charts, Talanta, v. 66, p. 11581167, 2005

MOGUERZA, J. M; MUÑOZ, A.; PSARAKIS, S. Monitoring Nonlinear Profiles using Support Vector Machines. Lecture Notes in Computer Science, 4756, p. 574-583. The publisher is Springer-Verlag, 2007.

MOSESOVA, S. A.; CHIPMAN, H. A.; MACKAY, R. J.; STEINER, S. H. Profile Monitoring Using Mixed-Effects Models, submitted for publication, 2007.

NOOROSSANA, R.; AMIRI, A.; SOLEIMANI, P. On the Monitoring of Autocorrelated Linear Profiles. To appear in Communications in Statistics-Theory and Methods, 2007a.

NOOROSSANA, R.; AMIRI, A.; VAGHEFI, S.A.; ROGHANIAN, E. Monitoring Process Performance Using Linear Profiles. Proceedings of the 3rd International Industrial Engineering Conference, Tehran, Iran, 2004a

NOOROSSANA, R.: SOLEIMANI, P. Effect of Within Profile Autocorrelation on the Performance of Linear Profiles. To appear in the Proceedings of the 5th International Industrial Engineering Conference, Tehran, Iran (in Farsi), 2007b.
NOOROSSANA, R : VAGHEFI, S. A. AMIRI, A. Effect of Non-normality on the Monitoring of Linear Profiles, Proceedings of the 2nd International Industrial Engineering Conference, Riyadh, Saudi Arabia, 2004b.

PACELLA, M.; SEMERARO, Q. An Unsupervised Neural Network Approach for On-line Monitoring of Machined Profiles. Presented at the 7th Annual Conference of ENBIS (European Network for Business and Industrial Statistic Dortmund, Germany, September 2426, 2007.

PARKER P. A.; FINLEY T. D. Advancements in Aircraft Model Force and Attitude nstrumentation by Integrating Statistical Methods. Journal of Aircraft, v. 44, p. 436443, 2007

REIS, M. S.; SARAIVA, P. M. Multiscale Statistical Process Control of Paper Surface Profiles", Quality Technology and Quantitative Management, v. 3, n. 3, p. 263-282, 2006

RUNGER, G. C.; BARTON, R. R.; DEL CASTILLO, E.; WOODALL, W. H. Optima Monitoring of Multivariate Data for Fault Detection, Journal of Quality Technology, v. 39, p. 159-172, 2007

SAHNI N. S.; AASTVEIT, A. H.; NAES T In-line Process and Product Contro using Spectroscopy and Multivariate Calibration. Journal of Quality Technology, v. 37 , p. $1-20,2005$

SCHAJER, G. S.; GAZZARRI, J. I.; WONG, D C.; MANESS, T. C.; KOZAK, R. A. Scanner System for Separate-Sided Lumber Surface Measurements. Forest Products Journal, v. 55, p. 175-180, 2005

STAUDHAMMER, C.; MANESS, T. C. KOZAK, R. A. Profile Charts for Monitoring Lumber Manufacturing Using Lase Range Sensor Data. Journal of Quality Technology, v. 39, p. 224-240, 2007a.

STAUDHAMMER, C.; MANESS, T. C. KOZAK, R. A. SPC Methods for Detecting Simple Sawing Defects Using Real-Time Laser Range Sensor Data. Wood and Fiber Science, v. 54, in press, 2007b.

WANG, K. B.; TSUNG, F. Using Profile Monitoring Techniques for a DataRich Environment with Huge Sample Size. Quality and Reliability Engineering International, v. 21, p. 677-688, 2005. 


\section{- References}

WILLIAMS, J. D.; BIRCH, J. B.; WOODALL, W. H.; FERRY, N. M. Statistical Monitoring of Heteroscedastic DoseResponse Profiles from High-Throughput Screening. Journal of Agricultural, Biological and Environmental Statistics, v. 12 , p. 216-235, 2007

WILLIAMS, J. D.; WOODALL, W. H. BIRCH, J. B. Statistical Monitoring of Nonlinear Product and Process Quality Profiles. Quality \& Reliability Engineering International, v. 23 , n. 7 , p. 925-941, 2007

WOODALL, W. H. Use of Control Charts in Health Care and Public Health Surveillance (with discussion). Journal of Quality Technology, v. 38, p. 89-104, 2006
WOODALL, W. H. Profile Monitoring, entry in Encyclopedia of Statistics in Quality and Reliability edited by Fabrizio Ruggeri, Frederick Faltin, and Ron Kenett, John Wiley \& Sons Ltd, 2007.

WOODALL, W. H.; SPITZNER, D. J.; MONTGOMERY, D. C.; GUPTA, S. Using Control Charts to Monitor Process and Product Quality Profiles. Journal of Quality Technology, v. 36, p. 309-320, 2004.

YOUNG, T. M.; WINISTORFER, P. M.; WANG, S. Multivariate Control Charts of MDF and OSB Vertical Density Profile Attributes. Forest Products Journal, v. 49, p. 79-86, 1999.

ZHOU, H.; LAWSON, A. B. EWMA Smoothing and Bayesian Spatial
Modeling for Health Surveillance. Under revision, 2007.

ZHOU, S.; JIN, N.; JIN, J. Cycle-based Signal Monitoring using a Directionally Variant Multivariate Control Chart System. IIE Transactions, v. 37, p. 971982, 2005.

ZHOU, S. Y. SUN, B. C.; SHI, J. J. An SPC Monitoring System for Cycle-based Waveform Signals using Haar Transform. IEEE Transactions on Automation Science and Engineering 2006, v. 3, n. 1, p. 60 72, 2006.

ZHU, J.; LIN, D. K. J. Monitoring the Slopes of Linear Profiles, paper presented at the Joint Statistical Meetings, Salt
Lake City, Utah and under revision for resubmission to the Journal of Quality Technology, 2007.

ZOU, C.; TSUNG, F.; WANG, Z Monitoring General Linear Profiles Using Multivariate Exponentially Weighted Moving Average Schemes. Technometrics, v. 49, n. 4, p. 395-408, 2007.

ZOU, C.; ZHOU, C.; WANG, Z.; TSUNG, F A Self-Starting Control Chart for Linear Profiles. Journal of Quality Technology, v. 39, n. 4, p. 364-375, 2007.

ZOU, C.; ZHANG, Y.; WANG, Z. A Control Chart Based on a Change-Point Model for Monitoring Profiles. IIE Transactions v. 38, p. 1093-1103, 2006

\section{- Acknowledgment}

The author appreciates the cooperation of a number of authors in sharing their unpublished work.

\section{- About the author}

\section{William H. Woodall}

Department of Statistics

Virginia Tech

Blacksburg, VA 24061-0439 U.S.A.

Email: bwoodall@vt.edu 